\title{
Thermodynamic performance analysis and simulation test of composite thermal insulation wall
}

\author{
Yi Hu, Changbing Chen* \\ Department of Civil Engineering, Hefei University, Hefei 230601, China
}

Corresponding Author Email: czb1108@hfuu.edu.cn

https://doi.org/10.18280/ijht.360404

Received: 18 January 2018

Accepted: 25 June 2018

\section{Keywords:}

thermal insulation building wall, thermodynamic analysis, temperature field, temperature stress, simulation

\begin{abstract}
Buildings accounts for more than $25 \%$ of the total energy consumption of our society, calling for better building energy-saving measures to improve the insulation performance of building walls. This paper explores the thermodynamic parameters (e.g. temperature field and temperature stress) of building thermal insulation wall. Firstly, the variation law of the temperature field of the building wall was simulated under the condition of external insulation structure; on this basis, the external insulation structure was compared with the internal insulation structure in terms of temperature stress variation. The research conclusions are as follows: The insulation materials in the wall significantly reduced the energy exchange between the indoor and outdoor environments. Under intense solar radiation, the surface temperature of the external wall was mainly affected by solar radiation; under weak solar radiation, the surface temperature of the external wall was mainly affected by the ambient temperature. Owing to the insulation layer, the temperature on the inner surface of the wall changed far slower than the external wall temperature. The temperature varied insignificantly from the surface of the inner wall to the inner surface of insulation layer, but significantly within the insulation layer. In the external insulation wall, the outermost decorative surface and the crack-resistant mortar layer both had a small temperature difference between the inner surface and the outer surface, witnessed a negative correlation between the surface temperature and temperature stress, and suffered mainly from tensile stress. Under significant variation of the ambient temperature, the two layers are likely to crack under the huge stresses. In winter, the base layer of the external insulation structure mainly suffered from compressive stress, while that of the internal insulation structure from tensile stress. In general, the external insulation structure can better protect the structural layer of the wall than the internal insulation structure, and effectively suppress the escape of indoor energy. The research findings lay a theoretical basis for the engineering application of the building wall insulation technology (BWIT) and shed new light on the prevention of wall durability problems (e.g. cracking and breaking) caused by temperature stress changes.
\end{abstract}

\section{INTRODUCTION}

Statistics show that buildings accounts for more than $25 \%$ of the total energy consumption of our society. This calls for better building energy-saving measures to improve the insulation performance of building walls [1-2].

Building wall insulation technology (BWIT) has become the main means of building energy conservation, thanks to its convenience and low cost in construction [3]. The BWIT adds energy-saving thermal insulation materials into the wall maintenance structure to save energy by controlling the energy transfer between the inside and outside of the building [4-5]. The latest thermal insulation wall mainly consists of such three parts as the base layer, the thermal insulation layer and the additional layer. Among them, the thermal insulation layer is the core to building energy conservation. It is usually made of materials like polystyrene board, polystyrene or aerated concrete [6-9].

Depending on the construction method, the BWIT can be divided into the external insulation technology of outer wall, the internal insulation technology of outer wall and the sandwich insulation technology [10-12]. The external insulation technology of outer wall is the most widely used construction method. However, the insulation layer is prone to cracking and aging in the service period because the insulation layer lies outside the base layer. The internal insulation technology of outer wall also has many defects, such as occupying indoor area and proneness to cold bridges and condensation [13-16].

To solve the above problems, this paper explores the thermodynamic parameters (e.g. temperature field and temperature stress) of building thermal insulation wall. Firstly, the variation law of the temperature field of the building wall was simulated under the condition of external insulation structure; on this basis, the external insulation structure was compared with the internal insulation structure in terms of temperature stress variation. The research findings lay a theoretical basis for the engineering application of the BWIT and shed new light on the prevention of wall durability problems (e.g. cracking and breaking) caused by temperature stress changes. 


\section{THERMODYNAMIC MODEL OF TEMPERATURE FIELD IN BUILDING INSULATION WALL AND ANALYSIS OF CALCULATION RESULTS}

\subsection{Building wall structure and initial parameters}

Figure 1 shows a typical external insulation structure of building wall as well as the width and materials of each layer. The period change of the external air temperature $T_{a}$ can be calculated as:

$T_{a}=-\sin \left[\frac{2 \pi\left(t_{d}+2\right)}{24}\right]\left(\frac{T_{\max }-T_{\min }}{2}\right)+\left(\frac{T_{\max }+T_{\min }}{2}\right)$

where $T_{\max }$ and $T_{\min }$ are the daily maximum and minimum temperatures, respectively.

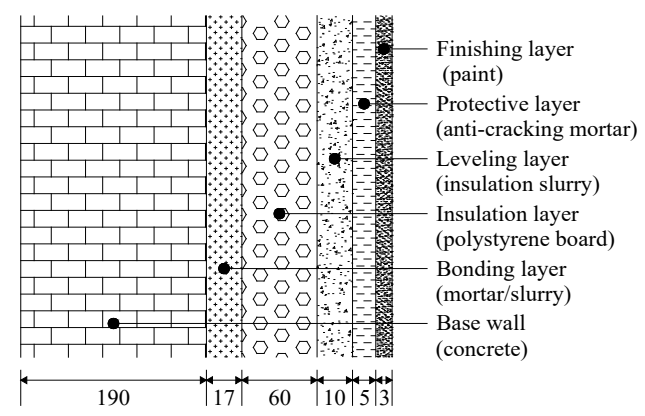

Figure 1. External insulation structure of building wall

\subsection{Mathematical model of building wall temperature field}

For simplicity, the building wall was considered as a mean structure, and the thermal resistance between the layers in Figure 1 was neglected. Then, the temperature at any position $(\mathrm{x}, \mathrm{y}, \mathrm{z})$ in the wall can be expressed as:

$\frac{\partial T}{\partial t}=\frac{\lambda}{\varphi}\left(\frac{\partial^{2} T}{\partial x^{2}}+\frac{\partial^{2} T}{\partial y^{2}}+\frac{\partial^{2} T}{\partial z^{2}}\right)$

where $\lambda$ and $\mathrm{c}$ are the thermal conductivity and the specific heat of the material, respectively. According to the actual test results, the temperature of the wall varies very slightly in the length $\mathrm{x}$ and width $\mathrm{y}$ directions. Hence, equation (2) can be normally simplified as:

$\frac{\partial T}{\partial t}=\frac{\lambda}{\varphi} \frac{\partial^{2} T}{\partial z^{2}}$

Then, the mathematical model of building wall temperature field can be set up with the following parameters: the indoor air temperature $T_{i n}$, the inner wall surface temperature $T_{i}$, the indoor heat exchange coefficient $\beta_{\text {in. Thus, the heat exchange }}$ amount $\mathrm{q}_{\text {in }}$ between the inner wall surface and the indoor can be expressed as:

$q_{\text {in }}=\beta_{\text {in }}\left[T_{\text {in }}(t)-\mathrm{T}_{i}(t)\right]$

Similarly, the heat exchange amount $\mathrm{q}_{\text {out }}$ between the outer wall and the outdoor can be expressed as:

$q_{\text {out }}=\beta_{\text {out }}\left[T_{\text {out }}(t)-T_{n}(t)\right]$

The solar radiation on the outer wall surface is subjected to the following boundary condition:

$q_{r}=\alpha_{S} I_{z}$

\subsection{Calculation results and analysis}

Figure 2 presents the winter temperature changes in the building walls with south-facing and north-facing external insulation structures, respectively. As shown in Figure 2, the indoor temperature changed periodically, but by a small amplitude $\left(<3^{\circ} \mathrm{C}\right)$; the insulation materials in the wall significantly reduced the energy exchange between the indoor and outdoor environments; the ambient air has a major impact on the temperature of the outside wall surface, as evidenced by the greater-than $-12^{\circ} \mathrm{C}$ temperature difference between the outer surface of the insulation layer and the outer surface of the south-facing wall.
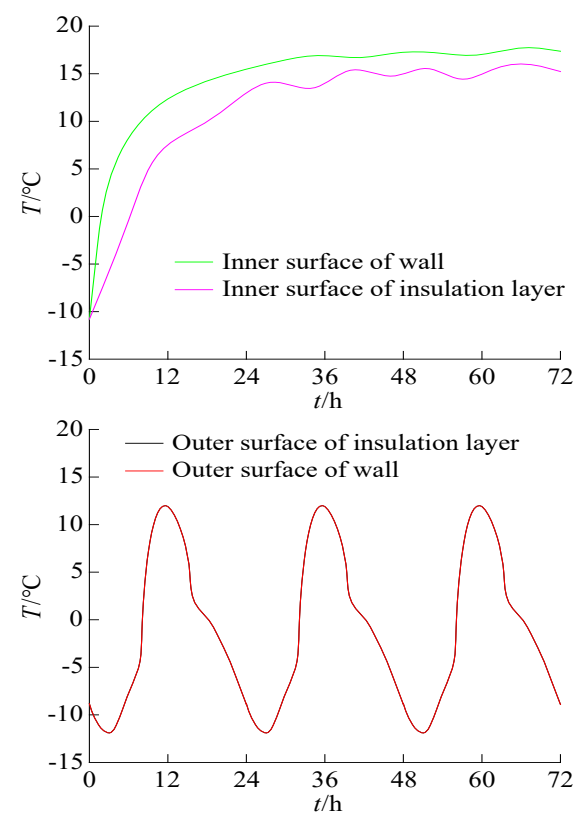

(a)South-facing wall
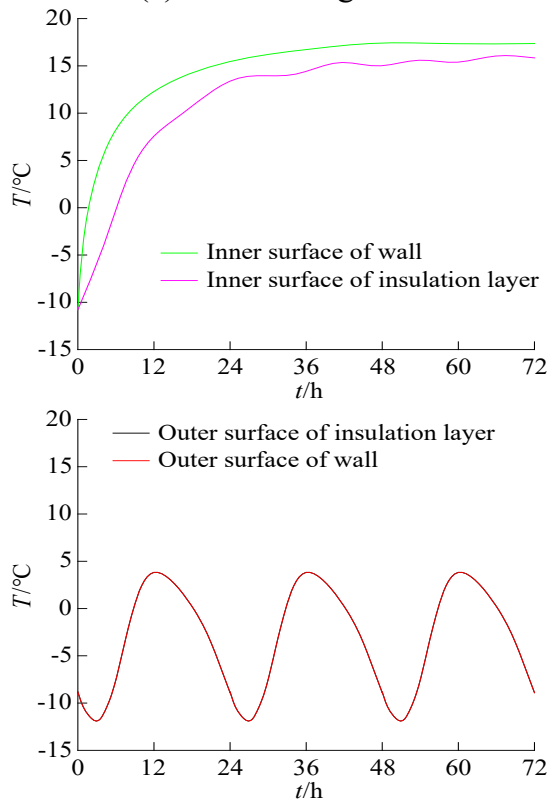

(b)North-facing wall

Figure 2. The winter temperature changes in the building walls with south-facing and north-facing external insulation structures 
Figure 3 shows the winter temperature changes in the building walls with south-facing and north-facing external insulation structures, respectively, under solar radiation. From Figures 2 and 3, it can be seen that the outer wall surface was warmer than the ambient air under solar radiation. When the solar radiation intensity was weak, the temperature of the outer wall started to decrease gradually, but with a certain delay compared with the variation in solar radiation intensity. The wall surface temperature was affected by different factors in different cases. Under intense solar radiation, the surface temperature of the external wall was mainly affected by solar radiation; under weak solar radiation, the surface temperature of the external wall was mainly affected by the ambient temperature. Owing to the insulation layer, the temperature on the inner surface of the wall changed far slower than the external wall temperature.
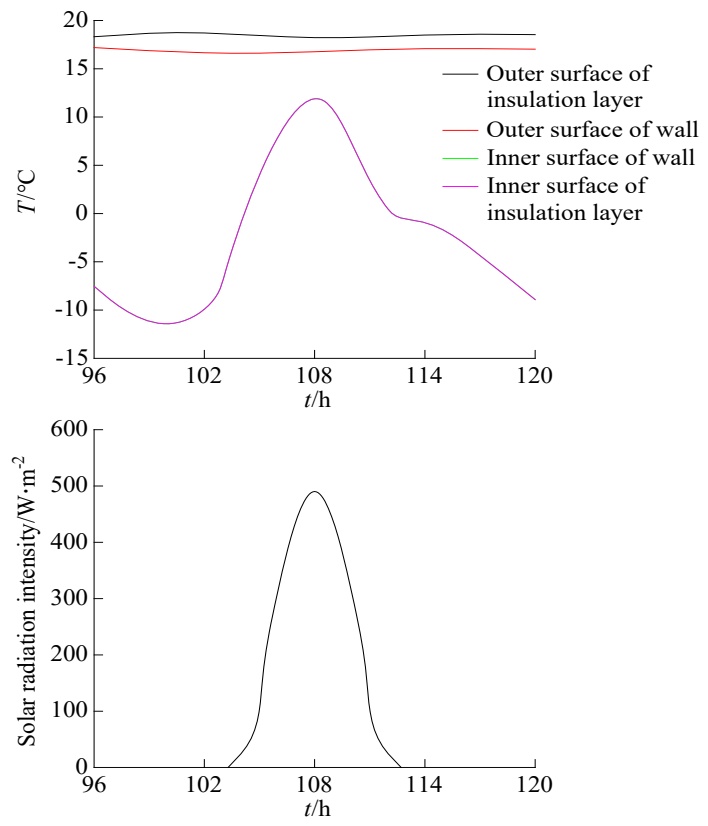

(a)South-facing wall
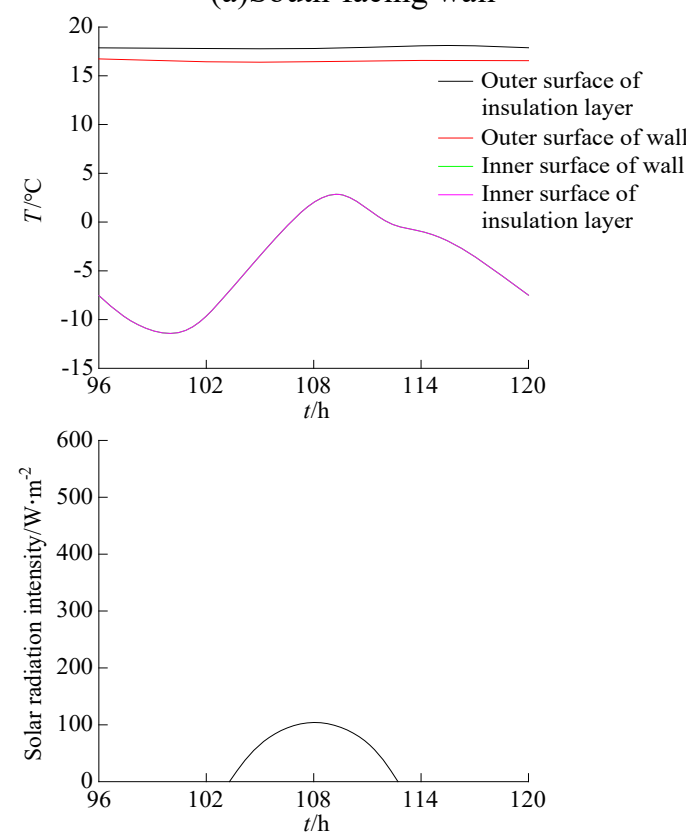

(b)North-facing wall

Figure 3. The winter temperature changes in the building walls with south-facing and north-facing external insulation structures under solar radiation.
The solar radiation also has a significant impact on the temperature field of the building wall. As shown in Figures 2 and 3 , the peak temperature of the south-facing wall stood at $13^{\circ} \mathrm{C}$, towering over that of the north-facing wall $\left(3.5^{\circ} \mathrm{C}\right)$, for the north-facing wall is less exposed to solar radiation than the south-facing wall. For both walls, the minimum temperature was around $-11{ }^{\circ} \mathrm{C}$. In addition, the maximum temperature difference of the south-facing wall reached $24^{\circ} \mathrm{C}$.

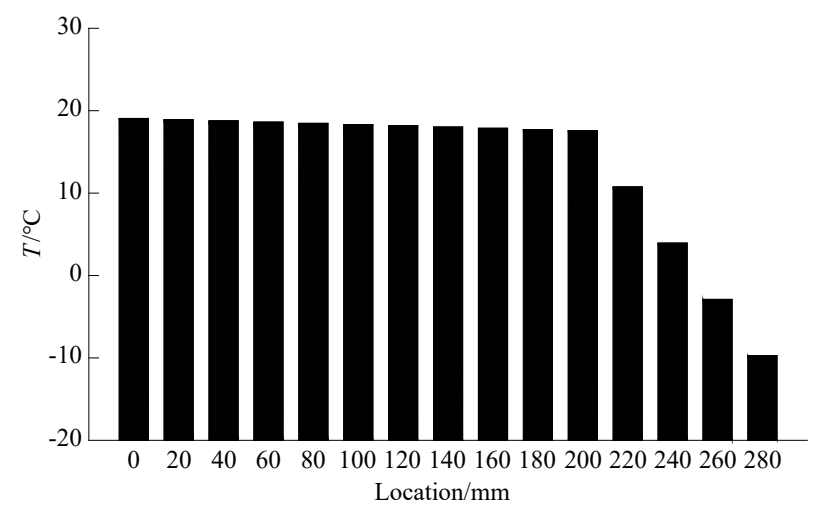

Figure 4. Winter temperature distribution of the wall in the thickness direction

The winter temperature distribution of the wall in the thickness direction is shown in Figure 4, where the origin $\mathrm{O}$ is the inner surface temperature of the wall and the $\mathrm{x}$-axis is the distance from the inner surface. Obvious, the temperature decreased very slowly from the inner wall surface indoor to the inner surface of the insulation layer, plunged rapidly in the insulation layer, and plummeted by nearly $30^{\circ} \mathrm{C}$ at the surface of the outer wall. This means the external insulation can effectively suppress the escape of indoor energy, making the base wall more stable and durable.

\section{ANALYSIS OF TEMPERATURE STRESS VARIATION IN BUILDING INSULATION WALL}

\subsection{Mathematical model of temperature stress}

Based on the above analysis, this section further investigates the temperature stress variation in building insulation wall. Equation (3) was simplified to express temperature field function $\mathrm{T}$ as a function of time $\mathrm{t}$ and wall thickness:

$T=f(t, z)$

Since the temperature stress is negligible in the length and width of the wall, this paper only considers the temperature stress variation in the thickness direction. After the addition of the insulation layer, the wall is composed of multiple layers of materials. Thus, the strain $\varepsilon$ of each layer under the effect of temperature stress can be expressed as:

$$
\begin{aligned}
& \varepsilon_{1}(z)=\alpha_{1}\left(A_{1}+B_{1} z_{1}\right) \\
& \varepsilon_{2}(z)=\alpha_{2}\left(A_{2}+B_{2} z_{2}\right) \\
& \varepsilon_{3}(z)=\alpha_{3}\left(A_{3}+B_{3} z_{3}\right) \\
& \cdots \cdots \\
& \varepsilon_{n}(z)=\alpha_{n}\left(A_{n}+B_{n} z_{n}\right)
\end{aligned}
$$


The parameters A and B can be derived from the following formulas:

$$
\begin{aligned}
& A_{1}=\frac{1}{h_{1}} \int_{-\frac{d_{1}}{2}}^{\frac{d_{1}}{2}}\left[T_{1}\left(z_{1}\right)-T_{10}\right] d z_{1} \\
& B_{1}=\frac{1}{h_{1}} \int_{-\frac{d_{1}}{2}}^{\frac{d_{1}}{2}}\left[T_{1}\left(z_{1}\right)-T_{10}\right] d z_{1} \\
& \quad \ldots \\
& A_{n}=\frac{1}{h_{n}} d \int_{-\frac{d_{n}}{2}}^{\frac{d_{n}}{2}}\left[T_{n}\left(z_{n}\right)-T_{n 0}\right] d z_{2} \\
& B_{n}=\frac{1}{h_{n}^{3}} d \int_{-\frac{d_{n}}{2}}^{\frac{d_{n}}{2}}\left[T_{n}\left(z_{n}\right)-T_{n 0}\right] z_{n} d z_{n}
\end{aligned}
$$

Then, the temperature stress $\sigma_{\mathrm{iT}}$ of the i-th layer material under full constraints is:

$\sigma_{i T}=-\frac{E_{i} \alpha_{i}\left(T_{i}-T_{i 0}\right)}{1-\mu}$

The temperature stress $\sigma_{i 1}$ of the i-th layer material under mean temperature is:

$\sigma_{i 1}=-\frac{E_{i} \alpha_{i}}{1-\mu} A_{i}$

The temperature stress $\sigma_{\mathrm{i} 2}$ of the i-th layer material under linear temperature is:

$\sigma_{i 2}=-\frac{E_{i} \alpha_{i}}{1-\mu} B_{i} z_{i}$

Considering the actual constraints of the wall, the temperature stress can be discussed in the following two cases:

Case 1: The wall is unconstrained, i.e. the freeform condition:

$\sigma_{i}=\sigma_{i 3}=\sigma_{i T}-\sigma_{i 1}-\sigma_{i 2}$

Case 2: The wall is fully constrained:

$\sigma_{i}=\sigma_{i T}$

The building insulation structure can be generally divided into the structural layer (reinforced concrete blocks) and the additional layer (insulation layer and protective structure). The additional layer, mainly anchored or pasted to the structural layer, has poor mechanical properties and often deforms simultaneously with the structural layer.

\subsection{Analysis of calculated temperature stress}

The temperature stresses of the external insulation and internal insulation walls were calculated based on the results of the temperature field acquired in the previous section. The first step is to analyze the situation that the insulation layer is outside the base wall. Figure 5 displays the temperature stress variation in the outermost decorative surface of the external insulation wall.

It can be seen that the outermost decorative surface had a small temperature difference between the inner surface and the outer surface, indicating that the temperature-induced bending stress was relatively small. When the wall was unconstrained, the temperature stress was basically zero, revealing that the temperature of the decorative layer obeyed a linear distribution. In addition, the surface temperature of the decorative layer is inversely proportional to the temperature stress, and the maximum temperature corresponds to the minimum temperature stress; the inverse is also true. In winter, the decorative surface was mainly subjected to tensile stress, which peaked at $0.55 \mathrm{MPa}$. The stress varied in a rang smaller than $0.5 \mathrm{MPa}$. Thus, the decorative surface is prone to cracking in winter.
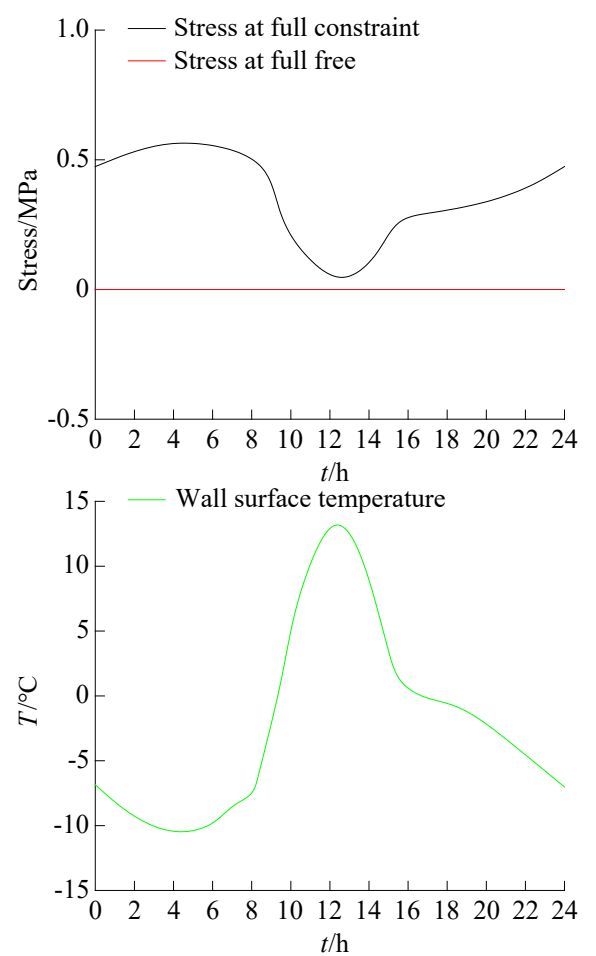

Figure 5. The temperature stress variation in the outermost decorative surface of the external insulation wall
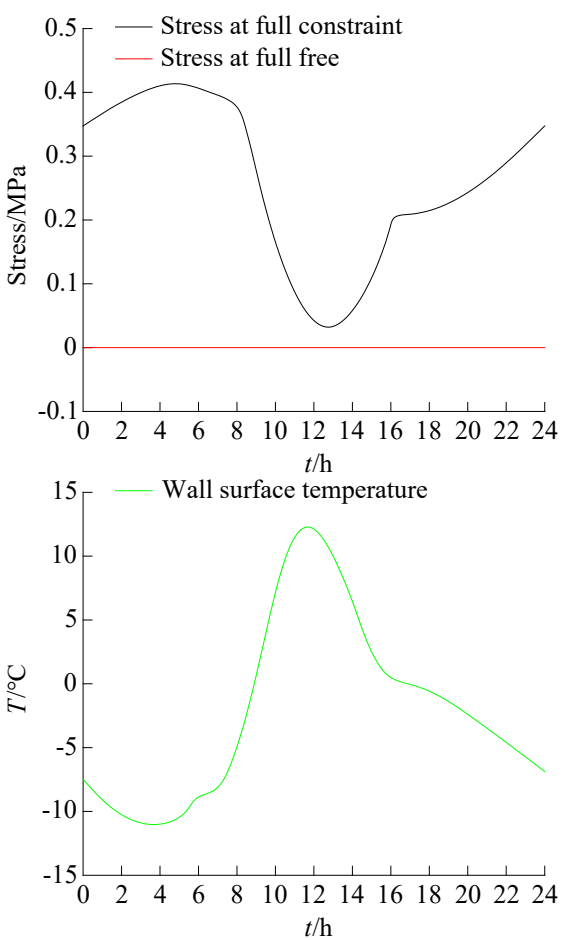

Figure 6. The temperature stress variation in the crackresistant mortar layer of the external insulation wall

Figure 6 illustrates the temperature stress variation of the crack-resistant mortar layer in the external insulation wall. It 
can be seen that the crack-resistant mortar layer also had a small temperature difference between the inner surface and the outer surface, indicating that the temperature-induced bending stress was relatively small. When the wall was unconstrained, the temperature stress was basically zero, revealing that the temperature of the decorative layer obeyed a linear distribution. In winter, the crack-resistant mortar layer was mainly subjected to tensile stress, which peaked at $0.4 \mathrm{MPa}$. The variation of stress was controlled within $0.4 \mathrm{MPa}$.

Figure 7 exhibits the temperature stress variation in the base layer of the external insulation wall. As shown in the figure, there was a certain difference between the inner and outer surfaces of the base layer, revealing a major impact of temperature on the bending stress of the base layer. When the wall was unconstrained, the temperature stress stood at zero, a sign of the small heat exchange between indoor and outdoor. The base layer was mainly subjected to compressive stress.
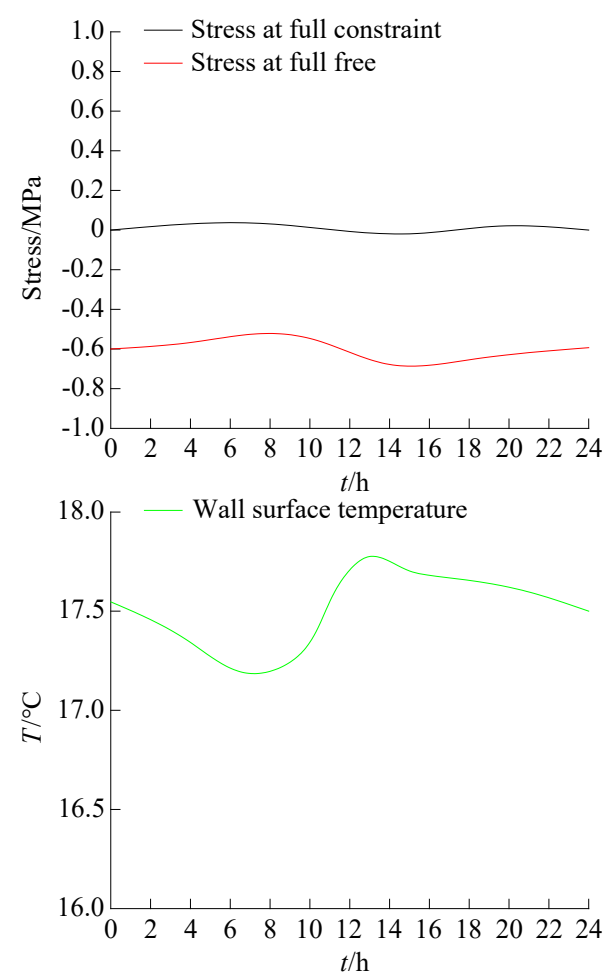

Figure 7. The temperature stress variation in the base layer of the external insulation wall

Next, the author analyzed the temperature stress variation in internal insulation wall. The temperature stress variation in the outermost decorative surface of the internal insulation wall is described in Figure 8, which shows that the outermost decorative surface of the internal insulation wall had a lower peak stress than that of the outer insulation wall, but shared a similar trend of stress variation with the latter. Figure 9 displays the temperature stress variation in the base layer of the internal insulation wall. Contrary to the base layer of the external insulation wall, the base layer of the internal insulation wall had a high peak stress and mainly suffered from tensile stress. This means the external insulation structure outperforms the internal insulation layer in the protection of the structure layer. Under significant temperature variation, the wall with external insulation structure is much likely to crack than that with internal insulation structure, because the base layer in internal insulation structure will suffer from greater tensile stress.
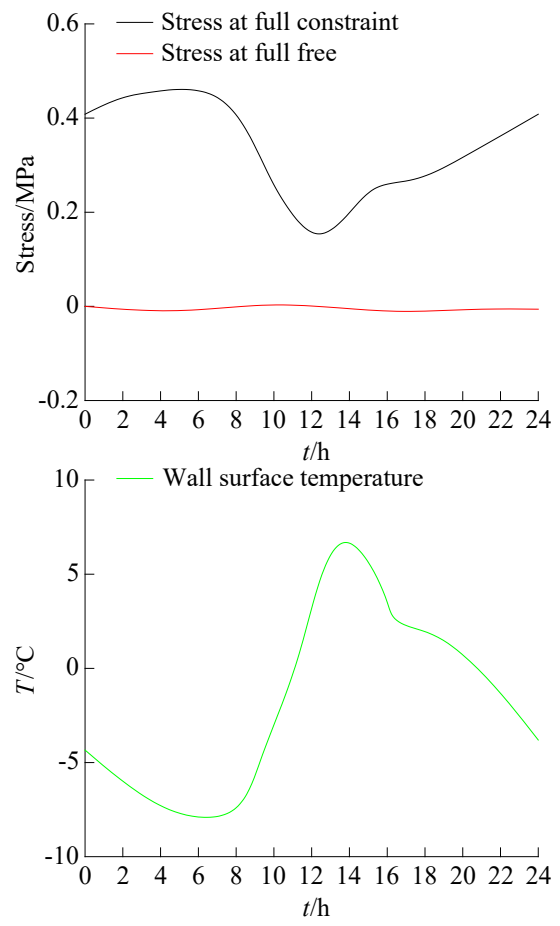

Figure 8. The temperature stress variation in the outermost decorative surface of the internal insulation wall
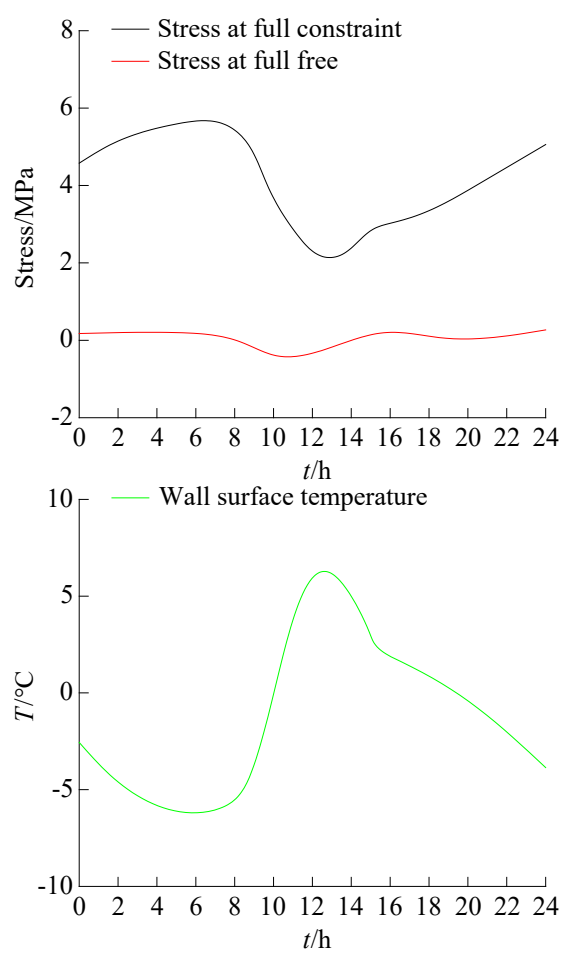

Figure 9. The temperature stress variation in the base layer of the internal insulation wall

\section{CONCLUSIONS}

This paper explores the thermodynamic parameters (e.g. temperature field and temperature stress) of building thermal insulation wall. Firstly, the variation law of the temperature field of the building wall was simulated under the condition of external insulation structure; on this basis, the external insulation structure was compared with the internal insulation 
structure in terms of temperature stress variation. The research conclusions are as follows:

(1) The insulation materials in the wall significantly reduced the energy exchange between the indoor and outdoor environments. Under intense solar radiation, the surface temperature of the external wall was mainly affected by solar radiation; under weak solar radiation, the surface temperature of the external wall was mainly affected by the ambient temperature. Owing to the insulation layer, the temperature on the inner surface of the wall changed far slower than the external wall temperature. The temperature varied insignificantly from the surface of the inner wall to the inner surface of insulation layer, but significantly within the insulation layer. The external insulation can effectively suppress the escape of indoor energy, making the base wall more stable and durable.

(2)In the external insulation wall, the outermost decorative surface and the crack-resistant mortar layer both had a small temperature difference between the inner surface and the outer surface, witnessed a negative correlation between the surface temperature and temperature stress, and suffered mainly from tensile stress. Under significant variation of the ambient temperature, the two layers are likely to crack under the huge stresses. In winter, the base layer of the external insulation structure mainly suffered from compressive stress, while that of the internal insulation structure from tensile stress. In general, the external insulation structure can better protect the structural layer of the wall than the internal insulation structure.

\section{ACKNOWLEDGEMENT}

This paper is supported by Major Natural Science Research Projects of Anhui Universities (Project No. KJ2018ZD054), 2018; Key project of natural science of Anhui University (Project No. KJ2017A543), 2017.

\section{REFERENCES}

[1] Liang Q, Liu JF, Liu J, Xu G. (2011). Effect of external wall insulation on building energy consumption. Applied Mechanics \& Materials 71-78: 156-159. https://doi.org/10.4028/www.scientific.net/amm.7178.156

[2] Cao L, Mu XN. (2014). Study on energy saving of external wall thermal insulation based on city green building. Applied Mechanics \& Materials 608-609: 1061-1065.

https://doi.org/10.4028/www.scientific.net/amm.608609.1061

[3] Ma LP, Wang Y, Jiang Q, Zhao CZ, Zhao P. (2015). Evaluation and selection research on external wall insulation materials based on green building energy conservation. Materials Science Forum 814: 524-532. https://doi.org/10.4028/www.scientific.net/msf.814.524

[4] Vilčeková S, Sedláková A, Kridlova-Burdova E, Ťažký L. (2014). Analysis of material solutions of exterior walls with contact thermal insulation system. Key Engineering Materials 635: 165-168 https://doi.org/10.4028/www.scientific.net/kem.635.165
[5] Ozel M. (2011). Thermal performance and optimum insulation thickness of building walls with different structure materials. Applied Thermal Engineering 31(17): 3854-3863. https://doi.org/10.1016/j.applthermaleng.2011.07.033

[6] Sun Q, Shi DX, Wang WB, Xu YS, Zhu L, Hu YF. (2014). Analyses the new building wall materials and exterior wall thermal insulation technology. Applied Mechanics and Materials 584-586: 1545-1550. https://doi.org/10.4028/www.scientific.net/amm.584586.1545

[7] Corvacho H, Ferreira T. (2012). On the use of internal thermal insulation systems for the retrofit of buildings exterior walls. Journal of Building Survey 97(9): 13601364.

[8] Cui HH. (2013). Structure and construction technology of new-type external thermal insulation in outer wall. Applied Mechanics \& Materials 353-356: 2813-2816. https://doi.org/10.4028/www.scientific.net/amm.353356.2813

[9] Zhu W. (2006). Introduction to heat insulation of building external wall. Industrial Construction 36(10): 23-23.

[10] Li G. (2014). Application analysis of the wall insulation construction technology in energy-saving of building. Applied Mechanics and Materials 556-562: 872-876. https://doi.org/10.4028/www.scientific.net/amm.556562.872

[11] Qian F. (2014). Insulation and energy-saving technology for the external wall of residential building. Advanced Materials Research 1073-1076: 1263-1270. https://doi.org/10.4028/www.scientific.net/amr.10731076.1263

[12] Li Y, Gong XZ, Zhang QH, Shi CQ. (2017). Energy consumption analysis of building with typical external thermal insulation system. Materials Science Forum 898: 190-1977. https://doi.org/10.4028/www.scientific.net/msf.898.197 0

[13] Zhang XJ, Liu YP. (2013). Study on building materials with exterior insulation system problems and solutions. Advanced Materials Research 788(788): 656-659. https://doi.org/10.4028/www.scientific.net/amr.788.656

[14] Cui HH. (2013). Structure and construction technology of new-type external thermal insulation in outer wall. Applied Mechanics and Materials 353-356: 2813-2816. https://doi.org/10.4028/www.scientific.net/amm.353356.2813

[15] Zhang XH, Liu JX, Zhang HZ. (2013). Building external wall thermal insulation construction quality safety measures analysis. Applied Mechanics \& Materials 253255:

646-649.

https://doi.org/10.4028/www.scientific.net/amm.253255.646

[16] Li Y, Gong XZ, Wang ZH, Li H, Fan MM. (2016). External insulation design impacts on the energy consumption and greenhouse gas emission of building. Materials Science Forum 847: 381-390. https://doi.org/10.4028/www.scientific.net/msf.847.381 